\title{
Synergism between $\alpha$-mangostin and TRAIL induces apoptosis in squamous cell carcinoma of the oral cavity through the mitochondrial pathway
}

\author{
MASAKATSU FUKUDA, HIDE SAKASHITA, HIROYASU HAYASHI, JUNYA SHIONO, \\ GENKI MIYAKE, YUSUKE KOMINE, FUYOKO TAIRA and HIDEAKI SAKASHITA \\ Division of Oral and Maxillofacial Surgery, Department of Diagnostic and Therapeutic Sciences, \\ Meikai University School of Dentistry, Saitama 350-0283, Japan
}

Received March 6, 2017; Accepted September 20, 2017

DOI: $10.3892 /$ or.2017.6030

\begin{abstract}
Mangosteen (Garcinia mangostana) is a tree found in South-East Asia and the pericarp of its fruit has been used in folk medicine for the treatment of many human illnesses. Mangosteen fruit rinds contain a high concentration of xanthone, which is a type of polyphenol. One type of xanthone, $\alpha$-mangostin, has been reported to exert chemopreventive effects against chemically-induced colon cancer through the decrease of c-Myc expression, suppressing tumor growth in a mouse model of mammary cancer. A recent study demonstrated the inhibitive effect of $\alpha$-mangostin on the growth of prostate cancer. However, it remains unclear whether $\alpha$-mangostin induces cell death in oral cancer. The present study examined the impact of $\alpha$-mangostin on human oral squamous cell carcinoma (HOSCC). Firstly we analyzed the expression of c-Myc in five HOSCC cell lines. The highest expression level of c-Myc mRNA was observed in SAS cells and the lowest in HSC-4 cells. Therefore, SAS cells were treated with $\alpha$-mangostin, which was found to exert a weak cytocidal effect. Since $\alpha$-mangostin has been reported to exert synergistic effects on cancers when combined with anticancer drugs, we attempted to evaluate such synergistic effects of $\alpha$-mangostin when used with a cytokine, tumor necrosis factor (TNF)-related apoptosis-inducing ligand (TRAIL). We found that the combination of $\alpha$-mangostin with TRAIL induced apoptosis of SAS cells through the mitochondrial pathway via activation of caspase- 9 and $-3 / 7$, following release of cytochrome $c$. This apoptosis was induced by S/G2/M-phase arrest. Immunopositivity for c-Myc was observed in the cytoplasm of
\end{abstract}

Correspondence to: Dr Masakatsu Fukuda, Division of Oral and Maxillofacial Surgery, Department of Diagnostic and Therapeutic Sciences, Meikai University School of Dentistry, 1-1 Keyakidai, Sakado, Saitama 350-0283, Japan

E-mail: fukudam@dent.meikai.ac.jp

Key words: $\alpha$-mangostin, xanthone, human oral squamous cell carcinoma, apoptosis, TRAIL tumor cells in $16(40 \%)$ of the 40 cases of HOSCC. These data revealed that the combination of $\alpha$-mangostin and TRAIL may have a considerable potential for the treatment of oral cancer.

\section{Introduction}

Human oral squamous cell carcinoma (HOSCC) is the most common malignant neoplasm arising in the mucosa of the upper aerodigestive tract. It is an aggressive tumor that is difficult to treat with conventional therapies, including chemotherapy, radiation and surgery. Since surgical treatment often profoundly affects the quality of life and daily activities of patients with HOSCC, new therapeutic strategies are necessary along with the other conventional treatments. Over the last several decades, epidemiological, preclinical and even early-phase clinical trials have revealed that selected dietary constituents may be promising for reducing the incidence of multiple cancers (1-3). Considering the potential that some of these phytochemicals have exhibited, it is essential to further identify and develop promising new agents in the hope of creating a broad spectrum of chemopreventive agents that can be used either alone or in combination against cancer. Phytochemicals extracted from natural sources, such as mangosteen, have recently been a focus of interest as anticancer drugs that may exert fewer side effects in patients with oral cancer.

Mangosteen (Garcinia mangostana L.) known as the 'queen of fruit' in its native Thailand can be found in many countries worldwide (4). For centuries, people in South-East Asia have used the dried mangosteen pericarp for medicinal purposes. It is used as an antiseptic, an anti-inflammatory, an antiparasitic, an antipyretic, an analgesic, as well as a treatment for skin rashes (5). Mangosteen fruit rind contains a high concentration of xanthone, which is a type of polyphenol. Over 200 xanthones are currently known to exist in nature and approximately 50 of them are found in mangosteen (5). $\alpha$-Mangostin has been identified as the most abundant xanthone and has therefore received the most attention for its health-promoting properties. It has recently been demonstrated to induce cell-cycle arrest and apoptosis in various types of human cancer cells (6-9). It has also been reported 
to exert chemopreventive effects against chemically-induced colon cancer by reducing the expression of c-Myc (5).

Tumor necrosis factor (TNF)-related apoptosis-inducing ligand (TRAIL), a member of the TNF superfamily, selectively induces apoptosis through the death receptors (DRs) DR4 and/or DR5 in cancer cells $(10,11)$. As these receptors are expressed on the surface of cancer cells, but not on the surface of normal cells, TRAIL is virtually inactive against normal cells. However, the application of TRAIL in anticancer treatment is limited because of its short half-life in serum and the development of resistance to TRAIL-induced apoptosis (12). On the other hand, it has recently been reported that a combination of $\alpha$-mangostin and TRAIL synergistically suppresses the growth of TRAIL-resistant cancer cells (13). Therefore, in the present study, we investigated the degree to which $\alpha$-mangostin can inhibit the growth of human oral cancer cells through induction of apoptosis and cell cycle arrest in vitro. In addition, we examined the synergistic effects of $\alpha$-mangostin in combination with TRAIL against oral cancer cells.

\section{Materials and methods}

Reagents. Rabbit anti-human c-Myc monoclonal antibody (mAb c-Myc) was purchased from Cell Signaling Technology (Danvers, MA, USA) for immunoblot analysis and immunohistochemistry (IHC). Mouse anti-human $\beta$-actin monoclonal antibody (mAb $\beta$-actin) and $\alpha$-mangostin were obtained from Sigma-Aldrich (St. Louis, MO, USA). Recombinant human TRAIL/Apo2L (rhTRAIL/Apo2L) was purchased from PeproTech (London, UK). $\alpha$-Mangostin and rhTRAIL were used for the stimulation of the cell lines. A Cytochrome $c$ Apoptosis Detection kit (including mouse anti-human cytochrome $c$ monoclonal antibody, mAb cytochrome $c$ ) was purchased from PromoKine (Heidelberg, Germany).

Cell culture. The HOSCC cell lines (HSC-2, HSC-3, HSC-4, Ca9-22 and SAS) were obtained from the Japanese Cancer Research Resources Bank (JCRB, Osaka, Japan) and were maintained in RPMI-1640 medium supplemented with $10 \%$ heat-inactivated fetal bovine serum (FBS), $100 \mathrm{IU} / \mathrm{ml}$ penicillin and $100 \mu \mathrm{g} / \mathrm{ml}$ streptomycin. They were grown to confluency in $25-\mathrm{cm}^{2}$ culture flasks at $37^{\circ} \mathrm{C}$ in a humidified $5 \% \mathrm{CO}_{2}$ incubator until required.

RNA extraction and real-time quantitative RT-PCR. Total RNA was extracted from monolayer HOSCC cells $\left(1 \times 10^{6}\right.$ cells $\left./ \mathrm{ml}\right)$ using the acid guanidinium phenol-chloroform (AGPC) method as previously described (14). To ascertain the expression patterns of the c-Myc gene in the HOSCC cell lines, especially in HSC-4 and SAS that are derived from lymph node metastasis of tongue cancer, after treatment with $\alpha$-mangostin $(20 \mu \mathrm{M})$, rhTRAIL (100 $\mathrm{ng} / \mathrm{ml})$, or $\alpha$-mangostin $(20 \mu \mathrm{M})+$ rhTRAIL $(100 \mathrm{ng} / \mathrm{ml})$, real-time quantitative RT-PCR (qRT-PCR) analyses were performed using a Bio-Rad iCycler system (Bio-Rad, Tokyo, Japan) and an iScript One-Step RT-PCR kit with SYBR Green I (Bio-Rad) according to the manufacturer's instructions. Briefly, the mRNAs were reversetranscribed into cDNAs at $50^{\circ} \mathrm{C}$ for $10 \mathrm{~min}$ and then the reverse transcriptase (RT) was inactivated at $95^{\circ} \mathrm{C}$ for $5 \mathrm{~min}$. The PCR amplification was performed for 45 cycles at $95^{\circ} \mathrm{C}$ for $10 \mathrm{sec}$ and at $56^{\circ} \mathrm{C}$ for $30 \mathrm{sec}$, followed by detection. The PCR primers were designed and synthesized by Sigma-Aldrich (Ishikari, Japan) following special design criteria for real-time PCR primers. The following primer sequences were used in the PCR reactions: c-Myc forward, CCAGCAGCGACTCTGAGGAG and reverse, TTGAGGACCAGTGGGCTGTG. Each sample was tested in triplicate and for each reaction the corresponding non-RT-treated mRNA sample was included as a negative control. The relative level of c-Myc mRNA in each sample was normalized against the mRNA level of GAPDH, a housekeeping gene. For GAPDH, the forward primer was CAGCCTCAAGATCATCAGCA and the reverse primer was ACAGTCTTCTGGGTGGCAGT. The results were analyzed using the Bio-Rad iCycler Software 3.0 and Microsoft Excel 97 and expressed as the fold induction in comparison to the amount of GAPDH mRNA (set at 1). The specificity of the PCR products was assessed on the basis of melting curve data and agarose gel electrophoresis to determine the product size and to establish that no by-products were formed.

Immunoblot analysis. The monolayer cells $\left(1 \times 10^{6}\right.$ cells $\left./ \mathrm{ml}\right)$ were lysed in cell lysis buffer containing $50 \mathrm{mM}$ Tris- $\mathrm{HCl}$ (pH 8.0), $150 \mathrm{mM} \mathrm{NaCl,} 0.02 \%$ sodium azide, $1 \%$ Triton $\mathrm{X}-100$, $1 \mu \mathrm{g} / \mathrm{ml}$ aprotinin and $100 \mu \mathrm{g} / \mathrm{ml}$ phenylmethylsulfonyl fluoride (PMSF) and then scraped from the dishes with a cell scraper (Nalge Nunc International, Naperville, IL, USA). After 20 min on ice, the lysate was centrifuged for $5 \mathrm{~min}$ at $15,000 \mathrm{rpm}$ at $4^{\circ} \mathrm{C}$ and the soluble supernatant fraction was used for western blot analysis. Protein concentrations were assessed using the Bio-Rad protein assay (Bio-Rad). For the detection of c-Myc and cytochrome $c$ proteins by gel electrophoresis, $10-\mu \mathrm{g}$ of protein samples were mixed with an equal volume of SDS-PAGE sample buffer and boiled for $5 \mathrm{~min}$. The samples were loaded in lanes and separated on $10 \%$ polyacrylamide gel and then the proteins were electroblotted onto polyvinylidene difluoride (PVDF) membranes (Bio-Rad). Non-specific binding sites on the membranes were blocked with $2 \%$ bovine serum albumin in phosphate-buffered saline (BSA-PBS) for $60 \mathrm{~min}$, followed by incubation with anti-c-Myc $\mathrm{mAb}$ $(1: 1,000)$, or anti-cytochrome $c \mathrm{mAb}(1: 1,000)$ for $60 \mathrm{~min}$ at room temperature. The filters were individually washed three times for $10 \mathrm{~min}$ in PBS containing 0.05\% Tween-20 (PBT). After incubation with a secondary horseradish peroxidase (HRP)-labeled goat anti-rabbit IgG $(\mathrm{H}+\mathrm{L})$ antibody $(1: 25,000)$ or an HRP-labeled rabbit anti-mouse $\operatorname{IgG}(\mathrm{H}+\mathrm{L})$ antibody (1:25,000; GE Healthcare, Piscataway, NJ, USA) for $60 \mathrm{~min}$ at room temperature, the filters were washed again three times for $10 \mathrm{~min}$ in PBT. Finally, the membranes were immersed for $5 \mathrm{~min}$ in ECL Plus western blotting reagent (GE Healthcare) and exposed for 2 min on Hyperfilm ECL (GE Healthcare) to obtain autoradiographs. Anti- $\beta$-actin mAb $(1: 5,000)$ was used as an internal control.

Cell viability assay. The assay is based on the cleavage of tetrazolium salt WST-8 to formazan by cellular mitochondrial dehydrogenases, the activity of which increases in proportion to the number of viable cells. The formazan dye produced by viable cells was quantified as an index of cell proliferation. Monolayer HSC- 4 and SAS cells $\left(2 \times 10^{4}\right.$ cells $/ 100 \mu \mathrm{l} /$ well $)$ were incubated for $24 \mathrm{~h}$ on a 96 -well plate. The cells were washed once 
with PBS and incubated with $\alpha$-mangostin $(20 \mu \mathrm{M})$, rhTRAIL (100 ng/ml), or $\alpha$-mangostin $(20 \mu \mathrm{M})+\operatorname{rhTRAIL~}(100 \mathrm{ng} / \mathrm{ml})$ for $24 \mathrm{~h}$ in RPMI-1640 medium containing $10 \%$ FBS. Ten microliters of WST-8/ECS solution (Dojindo Laboratories, Tokyo, Japan) was added to each well and incubated with the cells for $4 \mathrm{~h}$ at $37^{\circ} \mathrm{C}$ in a humidified $5 \% \mathrm{CO}_{2}$ incubator. The cells were then shaken thoroughly for $1 \mathrm{~min}$ on a shaker. After shaking, the relative number of viable cells was determined by assessing the absorbance of the dye solution at $450 \mathrm{~nm}$.

Apoptosis assay. The SAS cells were plated in white-walled 96-well tissue culture plates at a density of $5 \times 10^{3}$ cells/well in $100 \mu \mathrm{l}$ of medium and allowed to adhere for $24 \mathrm{~h}$. After incubation of the cells with $\alpha$-mangostin $(20 \mu \mathrm{M})$, rhTRAIL (100 ng/ml), or $\alpha$-mangostin $(20 \mu \mathrm{M})+\operatorname{rhTRAIL}(100 \mathrm{ng} / \mathrm{ml})$ for $24 \mathrm{~h}$, the activities of caspase-3/7, -8 and -9 were determined using the Caspase-Glo ${ }^{\circledR}$ 3/7, 8 and 9 assay (Promega, Madison, WI, USA) according to the manufacturer's instructions. Briefly, Caspase-Glo reagents were added to each well in a $50-\mu 1$ volume and incubated for $30 \mathrm{~min}$ before measurement of luminescence as relative light units (RLUs) using a Veritas Microplate Luminometer (Promega).

Analysis of cell cycle arrest. To determine the stage of the cell cycle at which the SAS cells were arrested, they were treated with $\alpha$-mangostin $(20 \mu \mathrm{M})+\operatorname{rhTRAIL}(100 \mathrm{ng} / \mathrm{ml})$ for $24 \mathrm{~h}$, and then examined using Fluorescent Ubiquitination-based Cell Cycle Indicator (FUCCI). FUCCI is a fluorescent cell cycle indicator that harnesses the ubiquitination oscillators that control cell cycle transitions. The original FUCCI probe was generated by fusing $\mathrm{mAG}$ (monomeric Azami-Green) and mKO2 (monomeric Kusabira-Orange 2) to the ubiquitination domains of human Geminin and Cdt1, respectively. These two chimeric proteins, mAG-hGem and mKO2-hCdt1, accumulate reciprocally in the nucleus of transfected cells during the cell cycle, labeling the nuclei of the S/G2/M-phase cells green and those in the G1 phase red. An mAG-hGem and an mKO2-hCdt1 expression vector were purchased from Medical and Biological Laboratories (Nagoya, Japan). To establish SAS cells transiently expressing $\mathrm{mAG}$ or $\mathrm{mKO} 2$, the parent cells were transfected with each plasmid using Lipofectamine (Invitrogen, Carlsbad, CA, USA) for $24 \mathrm{~h}$. The transfected cells were then treated with $\alpha$-mangostin $(20 \mu \mathrm{M})+\operatorname{rhTRAIL}(100 \mathrm{ng} / \mathrm{ml})$ or PBS as a control for $24 \mathrm{~h}$ and observed by fluorescence microscopy.

Cytochrome $c$ detection. Cytochrome $c$ was detected using a cytochrome $c$ apoptosis detection kit with an $\mathrm{mAb}$ cytochrome $c$ antibody according to the manufacturer's instructions. Briefly, after induction of apoptosis in the SAS cells, the cells were collected by centrifugation at $600 \mathrm{x} \mathrm{g}$ for $5 \mathrm{~min}$ at $4^{\circ} \mathrm{C}$ and washed with $10 \mathrm{ml}$ of ice-cold PBS. Subsequently the cells were resuspended in $1.0 \mathrm{ml}$ of $1 \mathrm{x}$ cytosol extraction buffer mix containing DTT and protease inhibitors and incubated on ice for $10 \mathrm{~min}$. The cells were homogenized by 50 passes with a Dounce tissue grinder on ice. The homogenate was transferred to a $1.5-\mathrm{ml}$ microcentrifuge tube, and centrifuged at $700 \mathrm{x} \mathrm{g}$ for $10 \mathrm{~min}$ at $4^{\circ} \mathrm{C}$. The supernatant was collected into a fresh $1.5-\mathrm{ml}$ tube as the cytosolic fraction and centrifuged at $10,000 \mathrm{x}$ g for $30 \mathrm{~min}$ at $4^{\circ} \mathrm{C}$. The pellet was resuspended in $0.1 \mathrm{ml}$ of mitochondrial extraction buffer mix containing DTT and protease inhibitors, vortexed for $10 \mathrm{sec}$ and saved as the mitochondrial fraction. Ten micrograms each of the cytosolic and mitochondrial fractions isolated from apoptosis-uninduced and -induced cells were then subjected to $10 \%$ SDS-PAGE, followed by standard western blotting and probed with anti-cytochrome $c$ mAb $(1 \mu \mathrm{g} / \mathrm{ml})$.

Primary tumor samples. Formalin-fixed, paraffin-embedded specimens were obtained from 40 patients with squamous cell carcinoma (SCC) treated at the Department of Oral and Maxillofacial Surgery, Meikai University Hospital, Japan. The pathological diagnosis of oral lesions was based on histological examination of hematoxylin and eosin (H\&E)-stained slides and made according to the WHO classification (15). The postsurgical TNM stage was determined according to the pTNM pathological classification of the International Union Against Cancer (UICC) (16). All specimens were obtained by surgical biopsy. None of the patients had undergone preoperative chemotherapy or radiotherapy. The labeling index was defined as the percentage of tumor cells displaying immunoreactivity and calculated by counting the number of c-Myc-positive cells among 1,000 tumor cells in each section. Tissue sections with $<5 \%$ immunoreactive cells were defined as negative and those with $>5 \%$ immunoreactive cells were defined as positive.

Immunohistochemical examination. For c-Myc staining, the sections were immersed in absolute methanol containing $0.3 \% \mathrm{H}_{2} \mathrm{O}_{2}$ for $20 \mathrm{~min}$ at room temperature to block endogenous peroxidase activity. After washing, each section was immersed in $0.01 \mathrm{M}$ citrate buffer ( $\mathrm{pH}$ 6.0) and heated in a microwave oven for $15 \mathrm{~min}$ as described by Shi et al (17). After washing with PBS ( $\mathrm{pH} 7.4$ ), the sections were incubated in $2 \%$ BSA-PBS for $15 \mathrm{~min}$ at room temperature to block non-specific reactions. Diluted anti-c-Myc mAb (1:50) was applied to each section for $60 \mathrm{~min}$ at room temperature. After washing with PBS, the slides were incubated with goat anti-rabbit $\operatorname{IgG}(\mathrm{H}+\mathrm{L})$ for c-Myc (1:200) for $30 \mathrm{~min}$ at room temperature. Diluted streptavidin-peroxidase $(1: 1,000)$ was then applied to the sections for $30 \mathrm{~min}$. After washing, the sections were immersed for $10 \mathrm{~min}$ in $0.05 \%$ 3,3'-diaminobenzidine tetrahydrochloride in $0.05 \mathrm{M}$ Tris- $\mathrm{HCl}$ buffer ( $\mathrm{pH} 7.6$ ) containing $0.01 \% \mathrm{H}_{2} \mathrm{O}_{2}$ and then counterstained with Mayer's hematoxylin.

Ethical considerations. The study was approved by the Research Ethics Committee of the Meikai University School of Dentistry, Saitama, Japan (reference no. A0801).

\section{Results}

Detection of the c-Myc gene expression in HOSCC cell lines. To examine differences in the expression of the c-Myc gene in HOSCC cell lines (HSC-2, HSC-3, HSC-4, Ca9-22 and SAS), qRT-PCR analysis was carried out using specifically designed primer pairs. c-Myc mRNA was endogenously expressed in all of the HOSCC cell lines. The highest level of expression was exhibited in the SAS cells and lowest in the HSC-4 cells (Fig. 1).

Expression of the c-Myc protein in HOSCC cell lines. SDS-solubilized extracts of the HOSCC cell lines were subjected to immunoblot analysis to determine the presence 


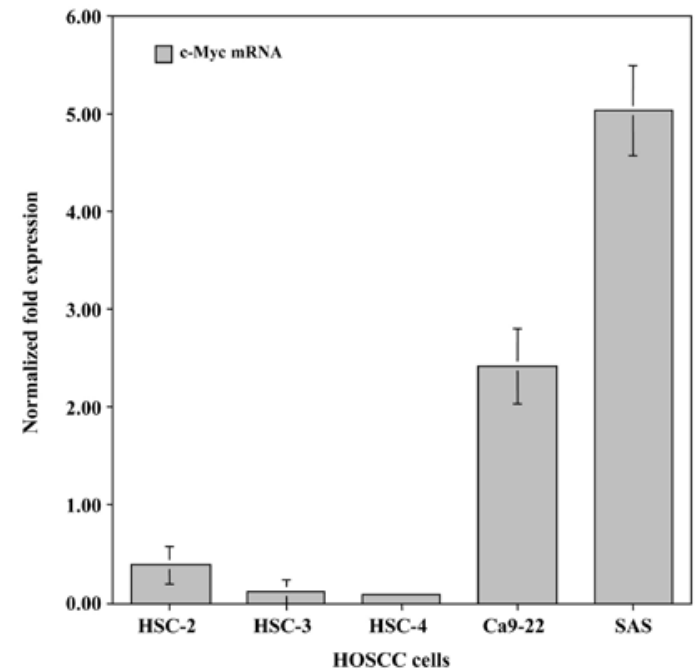

Figure 1. qRT-PCR. c-Myc mRNA was endogenously expressed in all the HOSCC cell lines. The highest levels of c-Myc mRNA expression were observed in SAS cells and the lowest in HSC-4 cells $(n=3$ experiments, means \pm SD). HOSCC, human oral squamous cell carcinoma.

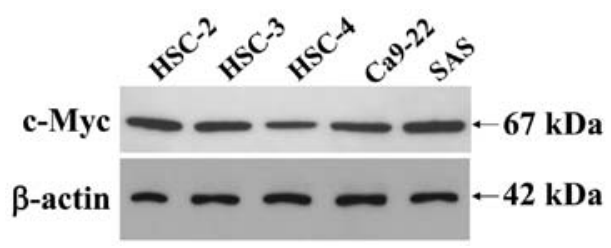

Figure 2. Western blot analysis. The c-Myc expressed in the HOSCC cell lines was a $67-\mathrm{kDa}$ peptide and it was weakly expressed in the HSC-4 cells and clearly expressed in the SAS cells by western blotting. HOSCC, human oral squamous cell carcinoma.

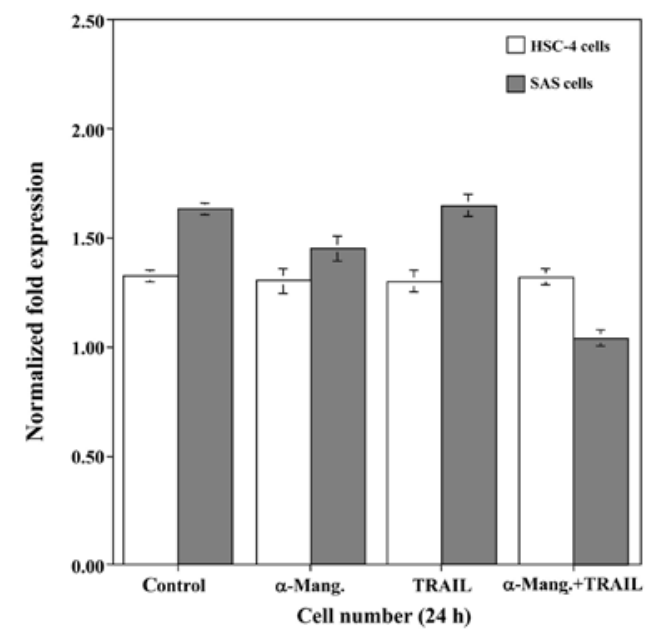

Figure 3. Cell viability analysis. The combination treatment with $\alpha$-mangostin and rhTRAIL significantly suppressed the proliferative activity of the SAS cells, but not that of the HSC- 4 cells $(n=3$ experiments, means \pm SD).

and quantity of c-Myc protein expression. Immunoblot analysis revealed that the c-Myc expressed in the cell lines was a $67-\mathrm{kDa}$ peptide and that it was clearly expressed in all of the HOSCC cell lines, although the weakest expression was observed in the HSC- 4 cells (Fig. 2). The $\beta$-actin protein was used as an internal

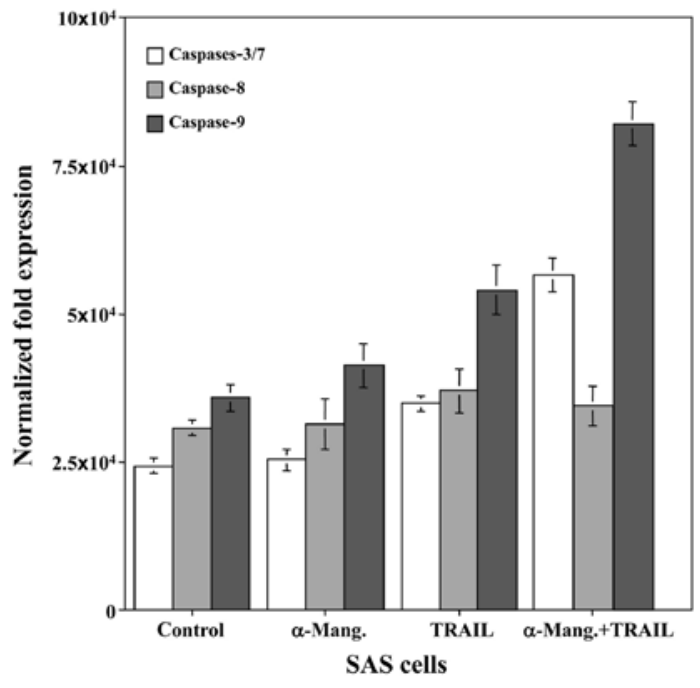

Figure 4. Apoptosis assay. The levels of caspase- 9 and $-3 / 7$ were increased in response to $\alpha$-mangostin and rhTRAIL, which exhibited more than a two-fold increase of activity at $24 \mathrm{~h}$ in the SAS cells relative to the control $(\mathrm{n}=3$ experiments, means $\pm \mathrm{SD})$.

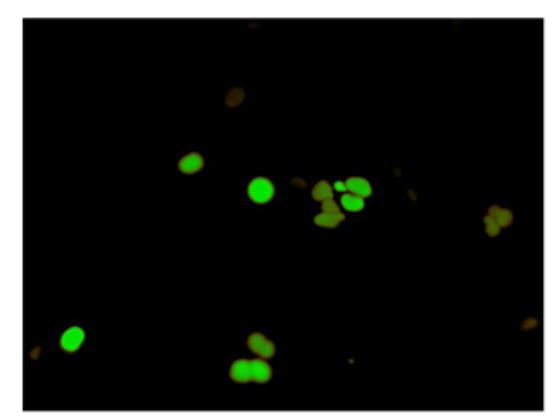

Figure 5. Cell cycle analysis. Treatment with both $\alpha$-mangostin and TRAIL induced S/G2/M-phase arrest and not G1-phase arrest, in SAS cells.

control, to assess the integrity of the protein extracted from the HOSCC cell lines, thus demonstrating that the protein obtained was intact.

Growth inhibition of oral cancer cells expressing c-Myc after combined treatment with $\alpha$-mangostin and rhTRAIL. From the results of the qRT-PCR, we attempted to determine whether $\alpha$-mangostin induced cell death of SAS and HSC-4 cells by carrying out a cell viability assay (Fig. 3). The treatment with $\alpha$-mangostin had a slight cytocidal effect on the SAS cells, whereas the viability of the HSC-4 cells was unaffected. Subsequently, to explore a possible adjuvant compound that would sensitize oral cancer cells to TRAIL-induced apoptosis, we examined the effect of rhTRAIL on SAS and HSC-4 cells. However, this had no effect on the viability of either cell line. Therefore, we examined the synergistic anti-proliferative effect of $\alpha$-mangostin $(20 \mu \mathrm{M})$ and rhTRAIL $(100 \mathrm{ng} / \mathrm{ml})$ on SAS and HSC-4 cells by incubating them with both for $24 \mathrm{~h}$. This combination treatment with $\alpha$-mangostin and rhTRAIL significantly suppressed the proliferative activity of the SAS cells, but not that of the HSC-4 cells. Accordingly, we focused on the SAS cells, which demonstrated high expression of c-Myc. 
Table I. Correlation between the expression of c-Myc and clinicopathological variables in 40 cases of HOSCC.

\begin{tabular}{|c|c|c|c|c|c|c|c|}
\hline No. & Age (years) & Sex & Location & Differentiation & pTNM & Stage & IHC, c-Myc \\
\hline 1 & 87 & M & Oral floor & Well & $\mathrm{T} 2 \mathrm{~N} 2 \mathrm{bM} 0$ & IVA & + \\
\hline 2 & 48 & $\mathrm{~F}$ & Gingiva & Well & T4N0M0 & IVA & - \\
\hline 3 & 56 & $\mathrm{~F}$ & Buccal mucosa & Well & T2N0M0 & II & - \\
\hline 4 & 75 & M & Tongue & Well & T4N2cM0 & IVA & + \\
\hline 5 & 55 & M & Oral floor & Well & T2N0M0 & II & + \\
\hline 6 & 54 & M & Tongue & Well & T4N2bM0 & IVA & - \\
\hline 7 & 54 & M & Oral floor & Well & T2N2aM0 & IVA & - \\
\hline 8 & 70 & M & Tongue & Well & T2NOM0 & II & - \\
\hline 9 & 67 & $\mathrm{M}$ & Maxillary gingiva & Well & T4N3M0 & IVB & - \\
\hline 10 & 92 & M & Soft palate & Well & T2NOM0 & II & - \\
\hline 11 & 66 & M & Tongue & Well & T2N0M0 & II & - \\
\hline 12 & 87 & M & Tongue & Well & T2N0M0 & II & - \\
\hline 13 & 48 & $\mathrm{~F}$ & Tongue & Well & T1N0M0 & $\mathrm{I}$ & - \\
\hline 14 & 85 & M & Tongue & Well & $\mathrm{T} 2 \mathrm{~N} 1 \mathrm{M} 0$ & III & + \\
\hline 15 & 56 & $\mathrm{~F}$ & Tongue & Well & $\mathrm{T} 1 \mathrm{~N} 2 \mathrm{bM} 0$ & IVA & + \\
\hline 16 & 67 & M & Mandibular gingiva & Well & T1N2bM0 & IVA & + \\
\hline 17 & 55 & M & Tongue & Well & T1N0M0 & I & + \\
\hline 18 & 85 & M & Buccal mucosa & Well & T1N0M0 & $\mathrm{I}$ & + \\
\hline 19 & 50 & M & Mandibular gingiva & Well & $\mathrm{T} 3 \mathrm{~N} 1 \mathrm{M} 0$ & III & + \\
\hline 20 & 67 & M & Mandibular gingiva & Well & T4N0M0 & IVA & + \\
\hline 21 & 79 & M & Buccal mucosa & Well & T2N0M0 & II & + \\
\hline 22 & 54 & $\mathrm{M}$ & Buccal mucosa & Well & T1N0M0 & I & - \\
\hline 23 & 54 & M & Mandibular gingiva & Well & T4N1M0 & IVA & - \\
\hline 24 & 62 & M & Mandibular gingiva & Well & T1N0M0 & $\mathrm{I}$ & + \\
\hline 25 & 60 & M & Maxillary gingiva & Well & T1N0M0 & $\mathrm{I}$ & + \\
\hline 26 & 79 & M & Mandibular gingiva & Moderate & T4N2cM0 & IVA & - \\
\hline 27 & 85 & $\mathrm{~F}$ & Tongue & Moderate & $\mathrm{T} 2 \mathrm{~N} 1 \mathrm{M} 0$ & III & - \\
\hline 28 & 54 & M & Tongue & Moderate & T1N0M0 & $\mathrm{I}$ & - \\
\hline 29 & 54 & M & Tongue & Moderate & T4N2bM0 & IVA & + \\
\hline 30 & 75 & M & Mandibular gingiva & Moderate & T1N0M0 & $\mathrm{I}$ & - \\
\hline 31 & 66 & $\mathrm{~F}$ & Mandibular gingiva & Moderate & T1N0M0 & $\mathrm{I}$ & - \\
\hline 32 & 65 & M & Mandibular gingiva & Moderate & T2N0M0 & II & - \\
\hline 33 & 88 & M & Mandibular gingiva & Moderate & T2N0M0 & II & - \\
\hline 34 & 79 & M & Mandibular gingiva & Moderate & T2N0M0 & II & - \\
\hline 35 & 54 & M & Buccal mucosa & Moderate & T2N0M0 & II & + \\
\hline 36 & 64 & M & Buccal mucosa & Poor & T2N0M0 & II & - \\
\hline 37 & 62 & M & Tongue & Poor & $\mathrm{T} 2 \mathrm{~N} 1 \mathrm{M} 0$ & III & - \\
\hline 38 & 60 & M & Tongue & Poor & $\mathrm{T} 2 \mathrm{~N} 1 \mathrm{M} 0$ & III & - \\
\hline 39 & 60 & M & Tongue & Poor & T1N0M0 & I & - \\
\hline 40 & 68 & M & Maxillary gingiva & Poor & T3N0M0 & III & + \\
\hline
\end{tabular}

c-Myc expression: $16 / 40$ cases (40\%). Tissue sections with $<5 \%$ immunoreactive cells were defined as negative (-) and those with $>5 \%$ immunoreactive cells were defined as positive (+). HOSCC, human oral squamous cell carcinoma; IHC, immunohistochemistry; M, male; F, female.

Induction of apoptosis in SAS cells by combined treatment with $\alpha$-mangostin and rhTRAIL. To determine whether caspase-dependent apoptotic activity could be modulated by combined treatment with $\alpha$-mangostin and rhTRAIL, the SAS cells were treated with $\alpha$-mangostin $(20 \mu \mathrm{M})$ and rhTRAIL (100 ng/ml), or left untreated as a control, for $24 \mathrm{~h}$. Subsequently, we examined the cleavage of procaspase to active caspase- $8,-9$ and $-3 / 7$, markers of apoptotic activity, in SAS cells. The levels of caspase- 9 and $-3 / 7$ were increased in response to $\alpha$-mangostin and rhTRAIL, which revealed more than a two-fold increase of activity at $24 \mathrm{~h}$, in the SAS cells relative to the control (Fig. 4). This finding indicated that the combined treatment with $\alpha$-mangostin and rhTRAIL led to apoptosis of the SAS cells via activation of caspase-3/7 and -9 . 


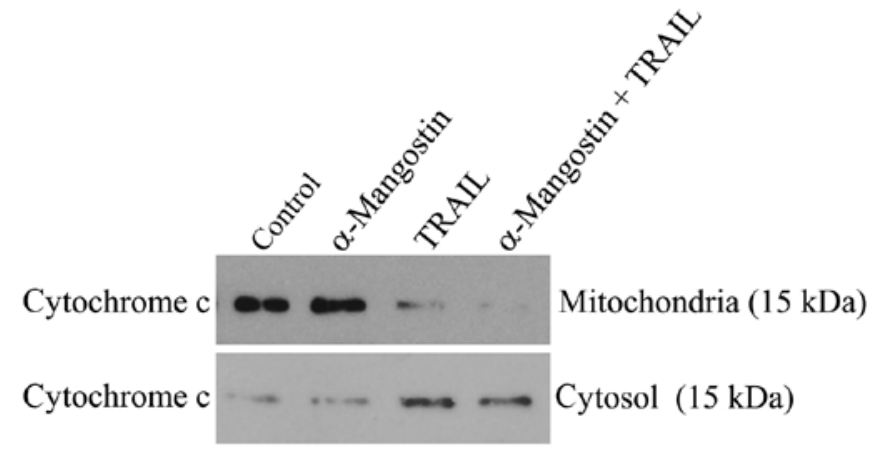

Figure 6. Release of cytochrome $c$ from the mitochondria into the cytosol. After treatment with $\alpha$-mangostin and rhTRAIL for $24 \mathrm{~h}$, cytochrome $c$ was detectable in the cytosolic fraction at a markedly higher level than in the control. In contrast, cytochrome $c$ protein was decreased in the mitochondrial fraction, indicating release of cytochrome $c$ from the mitochondria into the cytosol.

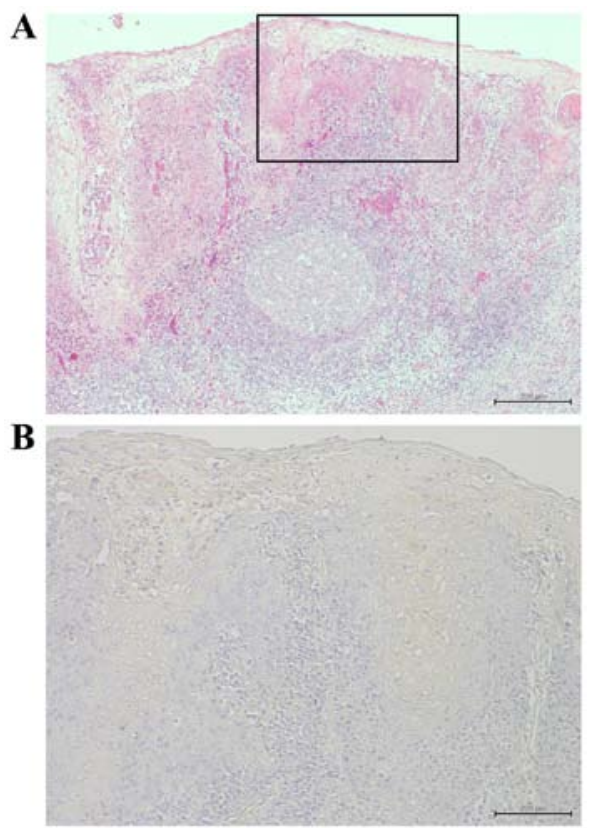

Figure 7. Histopathological examination. (A) H\&E stained specimen revealing a well-differentiated HOSCC (H\&E stain, original magnification, x40). (B) Immunohistochemical detection of c-Myc. Positivity for c-Myc was observed in the cytoplasm of the tumor cells in 16 of the 40 cases (40\%) (original magnification, x100). H\&E, hematoxylin and eosin. HOSCC, human oral squamous cell carcinoma.

We also used FUCCI to determine which stage of the cell cycle arrest occurred. This revealed that treatment with both $\alpha$-mangostin and TRAIL induced S/G2/M-phase arrest and not G1-phase arrest, in SAS cells (Fig. 5).

Release of cytochrome $c$ from the mitochondria into the cytosol. Release of cytochrome $c$ from the mitochondria is a critical step in the apoptosis cascade, since this activates downstream caspases. To investigate the release of cytochrome $c$ in SAS cells treated with $\alpha$-mangostin and rhTRAIL, we conducted western blot analysis of both the cytosolic and mitochondrial fractions. After treatment with $\alpha$-mangostin and rhTRAIL for $24 \mathrm{~h}$, cytochrome $c$ was detectable in the cytosolic fraction at a markedly higher level than in the control (Fig. 6). In contrast, cytochrome $c$ protein was decreased in the mitochondrial fraction, indicating release of cytochrome $c$ from the mitochondria into the cytosol.

Immunohistochemical detection of $c$-Myc and clinicopathological variables in HOSCC tissues. The correlations between the c-Myc expression and the clinicopathological variables in HOSCC tissues are summarized in Table I and Fig. 7A reveals an H\&E-stained specimen of well-differentiated HOSCC. Immunohistochemical detection of c-Myc was carried out in 40 cases of HOSCC at various stages. There were no correlations between the c-Myc expression and the clinicopathological variables. Positivity for c-Myc was observed in the cytoplasm of the tumor cells (Fig. 7B) in 16 of the 40 cases (40\%).

\section{Discussion}

Oral cancer accounts for $\sim 3-5 \%$ of all cancers $(18,19)$ and the clinical outcome of HOSCC has gradually improved. However, unlike cancers in other parts of the body, damage to the facial region can cause psychological disorders in patients and negatively affect their daily life, particularly in terms of eating or speaking. Therefore, there is a great interest in exploring potential treatments for oral cancer (20). Oral cancer poses a risk of invasion to adjacent organs and is associated with a high likelihood of metastatic recurrence. Therefore, combinations of surgical therapy, radiation and chemotherapy are usually employed. However, these treatments have low efficacy against cancer cell growth and micrometastasis and are associated with severe adverse effects and thus, the prognosis remains poor (21). It would therefore be valuable to find naturally-derived substances that specifically target cancer cells, exerting potent anticancer effects with limited side effects.

A large number of natural products have already been evaluated as potential chemopreventive or therapeutic agents, and among them, paclitaxel, etoposide, camptothecin and vincristine have also been applied as anticancer drugs. Among various phytochemicals, polyphenols (including xanthones) hold considerable promise as chemopreventive agents because of their antioxidative and potential anticancer activities $(22,23)$. A previous study has demonstrated the potent antiproliferative activity of four xanthones ( $\alpha$-mangostin, $\beta$-mangostin, $\gamma$-mangostin and methoxy- $\beta$-mangostin) isolated from the pericarp of mangosteen, against human leukemia HL60 cells (5). $\alpha$-Mangostin in particular, has recently been demonstrated to induce cell-cycle arrest and apoptosis in various types of human cancer cells (6-9). It has also been demonstrated to inhibit the invasion and migration of mammary and prostate cancer cells, associated with the downregulation of MMP-2 and MMP-9 (24,25). Furthermore, $\alpha$-mangostin has been shown to induce mitochondrial dysfunction in human leukemia HL60 cells (7). However, the mechanisms responsible for the apoptosis induced by $\alpha$-mangostin in oral cancer cells remain unknown. $\alpha$-Mangostin has also been reported to exert chemopreventive effects against chemically induced colon cancer via reduction of the c-Myc expression (5).

Cytokines are a large family of secreted proteins that bind to and signal through defined cell surface receptors on a wide variety of target cells and play a pivotal role in the establishment and maintenance of homeostasis. Many cytokines share structural features and functions during development, immune 
responses or inflammation. TRAIL/Apo2L has been identified as a member of the TNF superfamily (10). TRAIL is a type 2 transmembrane protein that functions in extracellular signaling through the DRs, DR4 and/or DR5 (11). When stimulated by this ligand, DRs recruit Fas-associated death domain (FADD) protein and its initiator caspase- 8 , resulting in formation of the death-inducing signaling complex (DISC). The recruited caspase- 8 undergoes autocatalytic cleavage and activation to trigger the cascade that ultimately leads to apoptosis (26). With virtually no toxicity toward normal cells, recombinant human TRAIL or agonistic antibodies specifically targeting DR5 are currently being tested in several clinical trials. However, their application for anticancer treatment is limited because of their short half-life in serum and the development of resistance to TRAIL-induced apoptosis (12). Moreover, it has been reported (13) that $\alpha$-mangostin functions as a sensitizer of TRAIL-induced apoptosis and can become a possible adjuvant compound for cytokine therapy to overcome TRAIL resistance in cancer cells. Accordingly, we hypothesized that a combination treatment with $\alpha$-mangostin and TRAIL may induce apoptosis in cancer cells, especially those expressing c-Myc.

In the present study, qRT-PCR and immunoblot analysis were initially performed to confirm the expression of c-Myc in five HOSCC cell lines. The results indicated that the highest level of c-Myc expression was exhibited in SAS cells and the lowest in HSC-4 cells. To investigate whether $\alpha$-mangostin would induce cell death in SAS and HSC-4 cells, a cell viability assay was performed. Treatment with $\alpha$-mangostin had a slightly cytocidal effect on the SAS cells, whereas it had no effect on the viability of the HSC-4 cells. Subsequently, to ascertain whether TRAIL would be effective as a cytokine therapy against oral cancer, we examined the effect of rhTRAIL on SAS and HSC-4 cells, however no effect on the viability of either cell line was observed. Therefore, to explore the possibility that $\alpha$-mangostin may sensitize oral cancer cells to TRAIL-induced apoptosis, a treatment with a combination of $\alpha$-mangostin and rhTRAIL was carried out. We found that this significantly suppressed the proliferative activity of SAS cells, but not that of HSC-4 cells. Subsequently, we focused on SAS cells, which demonstrated high expression of c-Myc. To confirm whether the reduction in the number of SAS cells was due to apoptosis, caspase activities in the cells were analyzed and revealed that the combination of $\alpha$-mangostin and rhTRAIL led to the activation of caspase- 9 and $-3 / 7$. Furthermore, it was observed that the cell cycle of the SAS cells was arrested at the $\mathrm{S} / \mathrm{G} 2 / \mathrm{M}$ phase during the process of apoptotic cell death. There are two major pathways that trigger apoptosis: the extrinsic and the intrinsic pathway. The extrinsic, or death-receptor, pathway is mediated by a death-inducing signaling complex comprised of a Fas-associated death domain and procaspase-8, leading to activation of caspase- 8 and subsequently the downstream caspases (27). The intrinsic, or mitochondrial, pathway involves loss of mitochondrial membrane potential and release of cytochrome $c$ into the cytosol, where it binds to Apaf-1, allowing the recruitment of caspase- 9 and the formation of an apoptosome complex, leading to caspase- 3 activation and execution of apoptosis (28). Most microtubule inhibitors such as paclitaxel, doxetaxel, vincristine, vinblastine and colchicine induce growth arrest, subsequent inactivation of
Bcl-2 and finally, apoptotic cell death through the caspase9-dependent pathway (29). A previous study has demonstrated that $\alpha$-mangostin activated caspase- 9 and -3 , but not -8 , in HL60 cells, indicating that $\alpha$-mangostin may mediate the mitochondrial pathway of apoptosis (7). The findings of our present study were similar: combination treatment with $\alpha$-mangostin and rhTRAIL led to activation of the proteolytic degradation products of caspase- 9 and $-3 / 7$. In contrast, the level of caspase- 8 remained the same, indicating that apoptosis was induced through the caspase-dependent mitochondrial pathway. Furthermore, cytochrome $c$ release from mitochondria is a critical step in the apoptotic cascade, since this activates downstream caspases. To investigate the release of cytochrome $c$ in SAS cells treated with $\alpha$-mangostin and rhTRAIL, we conducted western blot analysis of both the cytosolic and mitochondrial fractions. After treatment with $\alpha$-mangostin and rhTRAIL, cytochrome $c$ was detectable in the cytosolic fraction of SAS cells at a markedly higher level than in the control. In contrast, cytochrome $c$ protein was decreased in the mitochondrial fraction, indicating the release of cytochrome $c$ from mitochondria into the cytosol. If TRAIL induced apoptotic death in SAS cells, caspase-8 would be activated through the death-receptor pathway. However, in the present study we found that caspase-9 was activated. In addition, release of cytochrome $c$ from the mitochondria into the cytosol was also increased. Therefore, the mechanism responsible for apoptotic death in SAS cells remained unclear. On the basis of the present findings, we further hypothesized that TRAIL functioned as a sensitizer of $\alpha$-mangostin-induced apoptosis. Furthermore, immunopositivity for the c-Myc protein was observed in 16 (40\%) of the 40 cases of HOSCC we examined and therefore a suitable approach for investigation of cases that are c-Myc-negative remains to be devised.

In conclusion, we revealed that combined treatment of the SAS oral cancer cell line, which exhibits high expression of c-Myc, with $\alpha$-mangostin and TRAIL leads to reduction of tumor growth. This antitumor effect, which involves induction of apoptosis and cell cycle arrest in the S/G2/M phase, may have a potential application as an immune-cytokine therapy against TRAIL-resistant cells. Further investigations of the role of $\alpha$-mangostin will be required to fully elucidate the mechanism of its anticancer effect and for the establishment of an $\alpha$-mangostin-based therapeutic strategy for oral cancer.

\section{References}

1. Johnson JJ: Carnosol: A promising anti-cancer and anti-inflammatory agent. Cancer Lett 305: 1-7, 2011.

2. Johnson JJ, Bailey HH and Mukhtar H: Green tea polyphenols for prostate cancer chemoprevention: A translational perspective. Phytomedicine 17: 3-13, 2010.

3. Johnson JJ and Mukhtar H: Curcumin for chemoprevention of colon cancer. Cancer Lett 255: 170-181, 2007.

4. Ji X, Avula B and Khan IA: Quantitative and qualitative determination of six xanthones in Garcinia mangostana L. by LC-PDA and LC-ESI-MS. J Pharm Biomed Anal 43: 1270-1276, 2007.

5. Akao Y, Nakagawa Y, Iinuma M and Nozawa Y: Anti-cancer effects of xanthones from pericarps of mangosteen. Int J Mol Sci 9: 355-370, 2008.

6. Matsumoto K, Akao Y, Ohguchi K, Ito T, Tanaka T, Iinuma M and Nozawa Y: Xanthones induce cell-cycle arrest and apoptosis in human colon cancer DLD-1 cells. Bioorg Med Chem 13: 6064-6069, 2005. 
7. Matsumoto K, Akao Y, Yi H, Ohguchi K, Ito T, Tanaka T, Kobayashi E, Iinuma M and Nozawa Y: Preferential target is mitochondria in alpha-mangostin-induced apoptosis in human leukemia HL60 cells. Bioorg Med Chem 12: 5799-5806, 2004.

8. Moongkarndi P, Kosem N, Kaslungka S, Luanratana O, Pongpan N and Neungton N: Antiproliferation, antioxidation and induction of apoptosis by Garcinia mangostana (mangosteen) on SKBR3 human breast cancer cell line. J Ethnopharmacol 90: 161-166, 2004.

9. Nakagawa Y, Iinuma M, Naoe T, Nozawa Y and Akao Y: Characterized mechanism of alpha-mangostin-induced cell death: Caspase-independent apoptosis with release of endonuclease- $\mathrm{G}$ from mitochondria and increased miR-143 expression in human colorectal cancer DLD-1 cells. Bioorg Med Chem 15: 5620-5628, 2007.

10. Wiley SR, Schooley K, Smolak PJ, Din WS, Huang CP, Nicholl JK, Sutherland GR, Smith TD, Rauch C, Smith CA, et al: Identification and characterization of a new member of the TNF family that induces apoptosis. Immunity 3: 673-682, 1995.

11. Griffith TS, Stokes B, Kucaba TA, Earel JK Jr, VanOosten RL, Brincks EL and Norian LA: TRAIL gene therapy: From preclinical development to clinical application. Curr Gene Ther 9: 9-19, 2009

12. Yuan K, Sun Y, Zhou T, McDonald J and Chen Y: PARP-1 regulates resistance of pancreatic cancer to TRAIL therapy. Clin Cancer Res 19: 4750-4759, 2013.

13. Kumazaki M, Shinohara H, Taniguchi K, Ueda H, Nishi M, Ryo A and Akao Y: Understanding of tolerance in TR AIL-induced apoptosis and cancelation of its machinery by $\alpha$-mangostin, a xanthone derivative. Oncotarget 6: 25828-25842, 2015.

14. Fukuda M, Horiuchi Y, Oku Y, Ishikawa M, Suka N, Suzuki S, Kusama K and Sakashita H: Induction of apoptosis in human salivary gland tumor cells by anti-NCAM antibody. Oncol Rep 14: 1143-1149, 2005.

15. Pindborg JJ, Reichart PA, Smith CJ and van der Waal I (eds): Histological Typing of Cancer and Precancer of the Oral Mucosa. World Health Organization International Histological Classification of Tumors. 2nd edition. Springer-Verlag Berlin Heidelberg, New York, pp11-38, 1997.

16. Sobin LH and Wittekind CH (eds): International Union Against Cancer (UICC) TNM Classification of Malignant Tumors. 6th edition. John Wiley and Sons, Inc., New York, 1997.
17. ShiSR,Key MEand Kalra KL: Antigen retrieval in formalin-fixed, paraffin-embedded tissues: An enhancement method for immunohistochemical staining based on microwave oven heating of tissue sections. J Histochem Cytochem 39: 741-748, 1991

18. Neville BW and Day TA: Oral cancer and precancerous lesions. CA Cancer J Clin 52: 195-215, 2002.

19. Silverman S Jr: Early diagnosis of oral cancer. Cancer 62 (Suppl 8): 1796-1799, 1988

20. Kim MY, Kim CS, Lee SH, Kim JW and Jang HJ: A clinicostatistical analysis of oral cancer patients for recent 8 years. J Korean Assoc Oral Maxillofac Surg 33: 660-668, 2007.

21. Lee EJ, Kim MJ and Myoung H: Change of the invasiveness with selective Cox-2 inhibition in an oral squamous cell carcinoma cell line, KB: Preliminary in vitro study. J Korean Assoc Oral Maxillofac Surg 33: 103-108, 2007.

22. Sun J, Chu YF, Wu X and Liu RH: Antioxidant and antiproliferative activities of common fruits. J Agric Food Chem 50: 7449-7454, 2002.

23. Temple NJ and Gladwin KK: Fruit, vegetables, and the prevention of cancer: Research challenges. Nutrition 19: 467-470, 2003.

24. Hung SH, Shen KH, Wu CH, Liu CL and Shih YW: Alphamangostin suppresses PC-3 human prostate carcinoma cell metastasis by inhibiting matrix metalloproteinase-2/9 and urokinase-plasminogen expression through the JNK signaling pathway. J Agric Food Chem 57: 1291-1298, 2009

25. Lee YB, Ko KC, Shi MD, Liao YC, Chiang TA, Wu PF, Shih YX and Shih YW: alpha-Mangostin, a novel dietary xanthone, suppresses TPA-mediated MMP-2 and MMP-9 expressions through the ERK signaling pathway in MCF-7 human breast adenocarcinoma cells. J Food Sci 75: H13-H23, 2010.

26. Kim SY, Kim JH and Song JJ: c-Cbl shRNA-expressing adenovirus sensitizes TRAIL-induced apoptosis in prostate cancer DU-145 through increases of DR4/5. Cancer Gene Ther 20: 82-87, 2013.

27. Cho SG and Choi EJ: Apoptotic signaling pathways: Caspases and stress-activated protein kinases. J Biochem Mol Biol 35: 24-27, 2002.

28. Green DR and Reed JC: Mitochondria and apoptosis. Science 281: 1309-1312, 1998

29. Wang LG, Liu XM, Kreis W and Budman DR: The effect of antimicrotubule agents on signal transduction pathways of apoptosis: A review. Cancer Chemother Pharmacol 44: 355-361, 1999. 